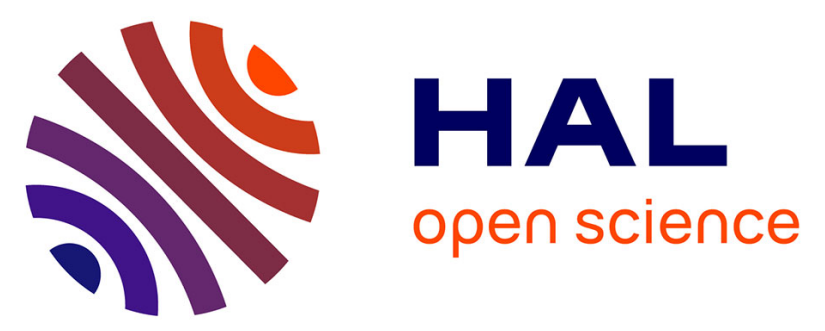

\title{
Should we look for anti-RNA polymerase III antibodies in systemic sclerosis patients with anti-centromere or anti-topoisomerase I antibodies?
}

Audrey Benyamine, Daniel Bertin, Xavier Heim, Brigitte Granel, Nathalie Bardin

\section{To cite this version:}

Audrey Benyamine, Daniel Bertin, Xavier Heim, Brigitte Granel, Nathalie Bardin. Should we look for anti-RNA polymerase III antibodies in systemic sclerosis patients with anti-centromere or anti-topoisomerase I antibodies?. European Journal of Internal Medicine, 2017, 44, pp.e42-e44. 10.1016/j.ejim.2017.07.033 . hal-01792225

\section{HAL Id: hal-01792225 \\ https://hal-amu.archives-ouvertes.fr/hal-01792225}

Submitted on 18 May 2018

HAL is a multi-disciplinary open access archive for the deposit and dissemination of scientific research documents, whether they are published or not. The documents may come from teaching and research institutions in France or abroad, or from public or private research centers.
L'archive ouverte pluridisciplinaire HAL, est destinée au dépôt et à la diffusion de documents scientifiques de niveau recherche, publiés ou non, émanant des établissements d'enseignement et de recherche français ou étrangers, des laboratoires publics ou privés. 


.

European Journal Of Internal Medicine

Letter to the Editor

\section{Should we look for anti-RNA polymerase III antibodies in Systemic Sclerosis patients} with anti-centromere or anti-topoisomerase I antibodies? Running title: anti-RNA polymerase III in Systemic Sclerosis

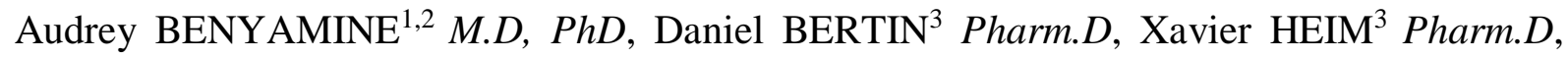
Brigitte GRANEL ${ }^{1,2}$ M.D, Nathalie BARDIN ${ }^{1,3}$ Pharm.D, PhD

1 Aix Marseille University, INSERM, VRCM, UMR_S 1076, Marseille, France

2 APHM, Hôpital Nord, Médecine interne, Marseille, France

3 APHM, Hôpital La Conception, Laboratoire d'Immunologie, Marseille, France

\section{Corresponding Author:}

\section{Audrey BENYAMINE}

Internal Medicine Department

Aix-Marseille Université - Hôpital Nord

13915 Marseilles, FRANCE

Tél: +33(0)491964513 - Fax : +33(0)491968080

Audrey.benyamine@ap-hm.fr

Reprint requests should be addressed to Audrey BENYAMINE, Hôpital Nord, Marseilles

2 The authors declare no conflict of interest.

3 Keywords: Systemic Sclerosis; Anti-RNA Polymerase III antibodies; Anti-centromere 24 Antibodies; Anti-topoisomerase I antibodies; Immunofluorescence pattern 
Systemic sclerosis ( $\mathrm{SSc}$ ) is a chronic autoimmune disease characterised by skin and internal organs fibrosis, vascular damage and positive antinuclear autoantibodies (ANAs). The classical antigenic specificities of ANAs are anti-centromere (ACA), anti-topoisomerase I antibodies (anti-topo I) and the more recently described anti-RNA polymerase III antibodies (anti-RNAPIII).

Anti-RNAPIII, firstly described in SSc in 1993[1], are currently admitted as specific SScrelated autoantibodies and have been incorporated into the 2013 ACR/EULAR classification criteria for the disease [2]. The prevalence of anti-RNAPIII partially depends on the geographic origin of patients [3]. In France, the prevalence is low and ranges from 3 to 9\% whereas it can reach $14 \%$ in North America and $41 \%$ in South America [3,4]. The ANA pattern associated with anti-RNAPIII was described as a fine-speckled nuclear stain with additional occasional bright dots, with or without concurrent punctate nucleolar staining but no typical pattern was proposed [5]. Anti-RNAPIII are mainly associated with a diffuse cutaneous subtype, scleroderma renal crisis and a risk of cancer in close temporal relationship to SSc onset $[3,4,6,7]$. As the specific method for their identification was the radioimmunoprecipitation assay, a cumbersome method not suitable for routine practice, these autoantibodies were not routinely looked for. More recently immunoenzymatic methods have been developed, but, the detection strategy was not clearly established for routine practice [5]. Although the positivity of ACA and anti-topo I is considered to be exclusive, the co-positivity of anti-RNAPIII with these SSc-specific auto-antibodies remains to be clarified. In order to design the best strategy for anti-RNAPIII detection, we aimed to 1 / evaluate the co-positivity of anti-RNAPIII in SSc patients positive for ACA or anti-topo I and to 2/ analyse immunofluorescence patterns and clinical characteristics of anti-RNAPIII positive patients. 
Firstly, 76 sera from SSc patients (9 men, 67 women) from Marseilles (South of France) positive for either ACA or anti-topo I antibodies were tested for the presence of antiRNAPIII. All patients fulfilled the 2013 ACR/EULAR criteria and were further classified as having diffuse or limited cutaneous SSc [2]. All the sera were collected from 2012 to 2016 and were issued from a Biobank (DC 2012-1704) with respect of ethical directives. Antinuclear antibodies (ANAs) were detected by indirect immunofluorescence on HEp-2 cells (Bio-Rad Laboratories, Hercules, CA) at a screening dilution of 1:160. ACA, anti-topo I and anti-RNAPIII were detected by commercially kits (EliA Thermo Fisher). The cutoff value for anti-RNAPIII positivity was 10 Arbitrary Unit/ml (AU).

Secondly, the ANAs immunofluorescence patterns and clinical data of $8 \mathrm{SSc}$ patients positive for anti-RNAPIII were collected from 2012 to 2016 and compared to anti-RNAPIII negative SSc patients $(<10 \mathrm{AU} / \mathrm{ml})$. Results were expressed as median $+/$ - interquartile range or as frequencies (fq). Medians were compared using Mann Whitney U Test. Frequencies were compared using Chi 2 Test.

Among the 76 selected sera of SSc patients, 33 patients (43\%) were positive for ACA and 43 (57\%) for anti-topo I antibodies. Immunofluorescence nuclear patterns were: centromeric $(n=32)$, nucleolar homogeneous $(n=41)$, speckled-centromeric $(n=1)$, speckled-homogeneous $(n=1)$ and mixed speckled-nucleolar-centromeric $(n=1)$. Anti-RNAPIII were investigated in these SSc patients: only one ACA-positive serum (1.3\%) was found also positive for antiRNAPIII with a titer of $192 \mathrm{AU} / \mathrm{ml}$. This serum corresponded to the mixed specklednucleolar-centromeric immunofluorescence nuclear pattern (Figure 1). No other specificities associated with a speckled pattern (anti-Ro/SSA anti-La/SSB, anti-Sm, anti-RNP) were detected. The patient, a 47-year-old female, had a diffuse cutaneous subset, with digital ulcers, joint contractures, a reduced diffuse lung capacity for carbon monoxide and oesophageal reflux disorder. Her medical history was remarkable for an ovarian 
adenocarcinoma that was diagnosed 6 years before SSc, and considered in remission after surgery and radio-chemotherapy.

Then, we retrospectively analysed immunofluorescence pattern and clinical characteristics of 8 SSc patients found positive for anti-RNAPIII in our laboratory. The various immunofluorescence aspects were nuclear speckled $(n=5)$, nucleolar $(n=1)$, nucleolarspeckled (n=1) (Figure 2) and mixed speckled-nucleolar-centromeric $(n=1)$ (Figure 1). The median titer of anti-RNAPIII was 54 [18-298] AU/ml.

Table 1 illustrates the comparison between anti-RNAPIII positive and negative patients. Sex ratio did not differ between the two groups. A trend to a higher frequency of the diffuse cutaneous form was observed in anti-RNAPIII positive SSc patients. The two patients with sine scleroderma belonged to the group of negative anti-RNAPIII. Scleroderma renal crisis was solely documented in patients with positive anti-RNAPIII. Other variables were not significantly associated with anti-RNAPIII positivity.

The present study extends the previously published data performed in South of France [4] about the anti-RNAPIII screening strategy. This study highlights that anti-RNAPIII are rarely encountered in SSc patients already positive for ACA or anti-topo I antibodies. The case of the patient with coexisting ACA and anti-RNAPIII was interesting regarding two aspects. First, the clinical feature was closer to the one described in patients with anti-RNAPIII with a diffuse cutaneous form and a concomitant cancer [8]. Second, the observed ANAs immunofluorescence pattern was highly remarkable due to the peculiar aspect of immunofluorescence. Therefore, in ACA or anti-topo I positive sera, the search for antiRNAPIII can be recommended faced to a mixed fluorescence pattern. Conversely, in case of typical fluorescence aspects related to ACA or anti-topo I positivity, the systematic search for anti-RNAPIII is not mandatory. As observed herein, different immunofluorescence pattern 
98

can be associated with anti-RNAPIII [9]. Therefore the search for this auto-antibody should

99 not be restrained to a nucleolar immunofluorescence pattern of ANAs [10].

100 Regarding the phenotype of anti-RNAPIII positive patients, a higher frequency of

101 scleroderma renal crisis and diffuse cutaneous form was observed. The low number of

102 patients and our geographic location might be a limiting factor to evidence any association

103 with other anti-RNAPIII features such as the frequency of cancer [8].

104 Although SSc-related autoantibodies are exclusive markers, co-positivity can exist in rare

105 cases. The immunofluorescence reading step appears crucial to focus the screening. In order

106 to improve the benefit cost ratio, anti-RNAPIII should be searched with respect to ANAs

107 fluorescence pattern and clinical characteristics of the patients.

108

\section{ACKNOWLEDGEMENT}

110 This research did not receive any specific grant from funding agencies in the public, 111 commercial, or not-for-profit sectors.

112 We thank internal medicine physicians for their help in collecting the clinical data (M.Ebbo,

113 N.Schleinitz, G.Kaplanski, C.Gomez). 
REFERENCES

116

117

118

119

120

121

122

123

124

125

126

127

128

129

130

131

132

133

134

135

136

137

138

139

140

141

142

143

144

145

146

147

148

149

150

151

152

153

154

[1] Kuwana M, Kaburaki J, Mimori T, Tojo T, Homma M. Autoantibody reactive with three classes of RNA polymerases in sera from patients with systemic sclerosis. J Clin Invest 1993;91:1399-404. doi:10.1172/JCI116343.

[2] van den Hoogen F, Khanna D, Fransen J, Johnson SR, Baron M, Tyndall A, et al. 2013 classification criteria for systemic sclerosis: an American College of Rheumatology/European League against Rheumatism collaborative initiative. Arthritis Rheum 2013;65:2737-47. doi:10.1002/art.38098.

[3] Sobanski V, Dauchet L, Lefèvre G, Lambert M, Morell-Dubois S, Sy T, et al. Prevalence of anti-RNA polymerase III antibodies in systemic sclerosis: New data from a French cohort and a systematic review and meta-analysis. Arthritis Rheumatol Hoboken NJ 2014;66:407-17. doi:10.1002/art.38219.

[4] Faucher B, Stein P, Granel B, Weiller P-J, Disdier P, Serratrice J, et al. Low prevalence of anti-RNA polymerase III antibodies in a French scleroderma population: anti-RNA polymerase III scleroderma. Eur J Intern Med 2010;21:114-7. doi:10.1016/j.ejim.2010.01.004.

[5] Parker JC, Burlingame RW, Webb TT, Bunn CC. Anti-RNA polymerase III antibodies in patients with systemic sclerosis detected by indirect immunofluorescence and ELISA. Rheumatol Oxf Engl 2008;47:976-9. doi:10.1093/rheumatology/ken201.

[6] Emilie S, Goulvestre C, Bérezné A, Pagnoux C, Guillevin L, Mouthon L. Anti-RNA polymerase III antibodies are associated with scleroderma renal crisis in a French cohort. Scand J Rheumatol 2011;40:404-6. doi:10.3109/03009742.2011.569753.

[7] Meyer O, De Chaisemartin L, Nicaise-Roland P, Cabane J, Tubach F, Dieude P, et al. Anti-RNA polymerase III antibody prevalence and associated clinical manifestations in a large series of French patients with systemic sclerosis: a cross-sectional study. J Rheumatol 2010;37:125-30. doi:10.3899/jrheum.090677.

[8] Lazzaroni M-G, Cavazzana I, Colombo E, Dobrota R, Hernandez J, Hesselstrand R, et al. Malignancies in Patients with Anti-RNA Polymerase III Antibodies and Systemic Sclerosis: Analysis of the EULAR Scleroderma Trials and Research Cohort and Possible Recommendations for Screening. J Rheumatol 2017. doi:10.3899/jrheum.160817.

[9] Codullo V, Morozzi G, Bardoni A, Salvini R, Deleonardi G, De Pità O, et al. Validation of a new immunoenzymatic method to detect antibodies to RNA polymerase III in systemic sclerosis. Clin Exp Rheumatol 2007;25:373-7.

[10] Yamasaki Y, Honkanen-Scott M, Hernandez L, Ikeda K, Barker T, Bubb MR, et al. Nucleolar staining cannot be used as a screening test for the scleroderma marker antiRNA polymerase I/III antibodies. Arthritis Rheum 2006;54:3051-6. doi:10.1002/art.22043. 
155 Table 1: Characteristics of SSc patients with respect to positivity of the anti-RNA

156 Polymerase III (anti-RNAPIII) autoantibodies.

\begin{tabular}{|c|c|c|c|}
\hline Characteristics & $\begin{array}{l}\text { Anti-RNAPIII + } \\
(n=8)\end{array}$ & $\begin{array}{l}\text { Anti-RNAPIII- } \\
(n=75)\end{array}$ & $\begin{array}{l}\mathrm{p}- \\
\text { value }\end{array}$ \\
\hline Sex Ratio (F/M) & $6 / 2$ & $66 / 9$ & 0.30 \\
\hline Age (years, median) [IQR] & $54[39.5-71.3]$ & $62.4[49.9-70.6]$ & 0.47 \\
\hline Age at disease onset (years, median) [IQR] & $52[30.5-71.8]$ & $53[43.8-61.3]$ & 0.77 \\
\hline $\begin{array}{l}\text { Age at the apparition of Raynaud } \\
\text { phenomenon (years, median) [IQR] }\end{array}$ & 48 [30-70.5] & $50[38-56]$ & 0.97 \\
\hline Diffuse SSc/Limited SSc & $5 / 3$ & $23 / 50$ & 0.08 \\
\hline Sine Scleroderma SSc & $0 / 8$ & $2 / 75$ & 0.64 \\
\hline Pulmonary fibrosis $(\mathrm{Fq})$ & $2 / 8$ & $25 / 70$ & 0.55 \\
\hline $\mathrm{FVC}(\%$, median $)[\mathrm{IQR}]$ & $87.6[70.2-108.3]$ & $79.5[68.8-100.5]$ & 0.49 \\
\hline DLCO $(\%$, median $)[\mathrm{IQR}]$ & $57[41-65]$ & $51.3[41.4-63.7]$ & 0.77 \\
\hline DLCO/VA (\%, median) [IQR] & $67[48-76]$ & $63.65[52-73]$ & 0.68 \\
\hline Pulmonary Arterial Hypertension (Fq) & $2 / 8$ & $20 / 72$ & 0.87 \\
\hline Esophagus Reflux Disorder (Fq) & $3 / 8$ & $24 / 65$ & 0.97 \\
\hline Intestinal Motility Disorder (Fq) & $1 / 8$ & $26 / 73$ & 0.26 \\
\hline Medsger Severity Scale $(\mathrm{Fq})$ & $3[3-4]$ & $3[2-3.37]$ & 0.27 \\
\hline Scleroderma Renal Crisis $(\mathrm{Fq})$ & $2 / 8$ & $0 / 75$ & $<10^{-4}$ \\
\hline Cancer occurrence & $1 / 8$ & $9 / 75$ & 0.96 \\
\hline Anti-Topo 1 antibody $(\mathrm{Fq})$ & $0 / 8$ & $43 / 75$ & - \\
\hline Anti-centromere antibody $(\mathrm{Fq})$ & $1 / 8$ & $32 / 75$ & - \\
\hline
\end{tabular}

157 Results are expressed as median + /- interquartile range or as frequencies (fq). Medians were

158 compared using Mann Withney U Test. Frequencies were compared using Chi 2 Test. 
Legends of the figures

160

161 Figure 1: The mixed fluorescence pattern (speckled-nucleolar-centromeric) of the ACA and 162 Anti-RNAPIII positive serum.

163 A: x 400 magnification.

164 B: Typical features of the centromeric pattern are highlighted with characteristic dots at the

165 interphase mitotic stage (left arrow) and a "block" of condensed dots at the metaphase stage

166 (right arrow).

167

168 Figure 2: Various immunofluorescence patterns obtained from sera positive for anti-RNAPIII

169 (x 400 magnification).

170 A: nuclear-speckled pattern

171 B: nucleolar-speckled pattern

172 C: nucleolar pattern

173 

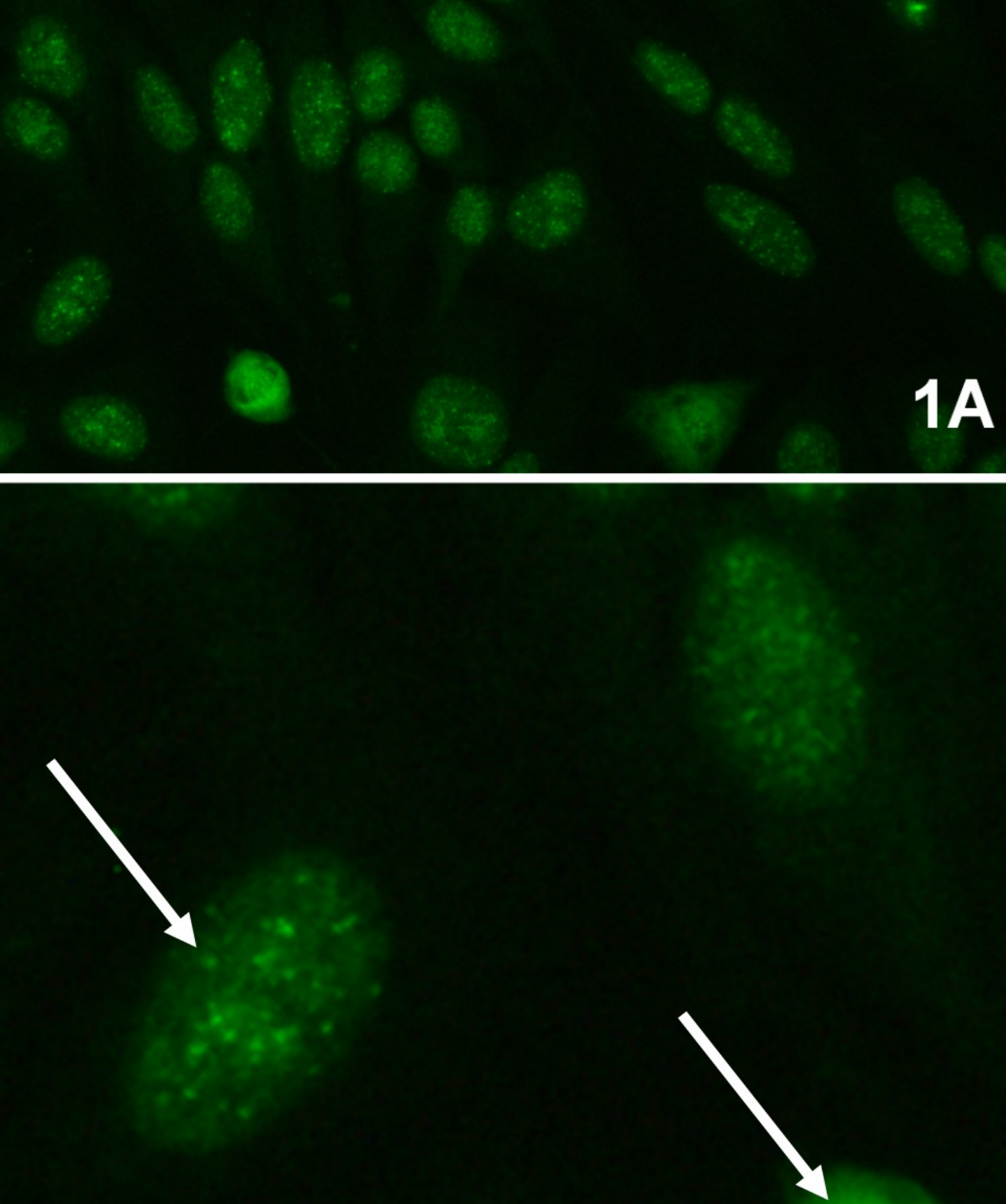


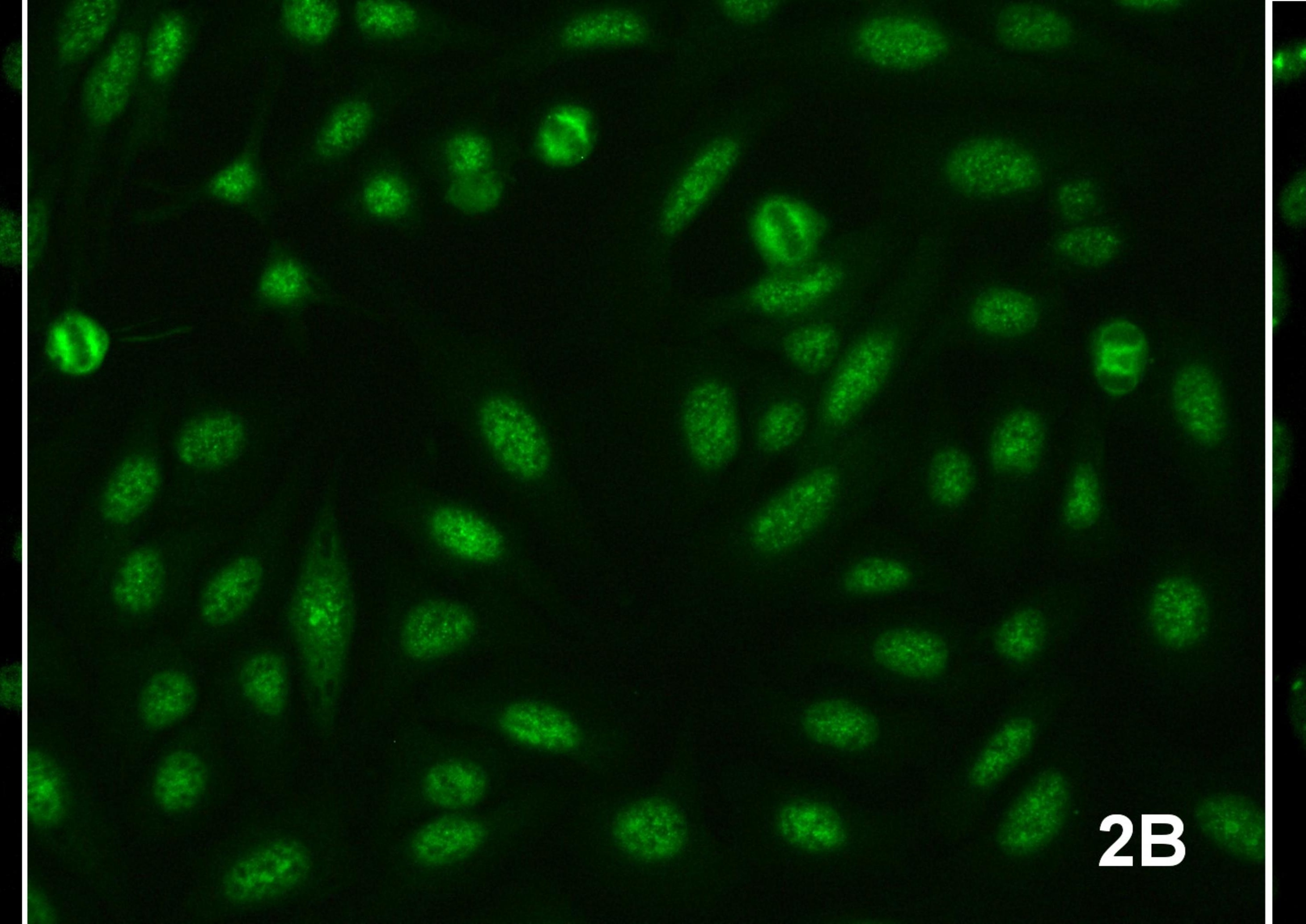

